\title{
The experience of Middle Eastern men living in Sweden of maternal and child health care and fatherhood: focus-group discussions and content analysis
}

\author{
Pernilla Ny, Masters in Internal Health, RN, RM (Doctoral Student) ${ }^{\mathrm{a}, *}$, Lars Plantin, PhD (Senior \\ (Assistant Professor) $^{\mathrm{b}}$ \\ ${ }^{a}$ Department of Health and Society, S-20506 Malmö, Malmö University, Sweden \\ ${ }^{\mathrm{b}}$ Department of Health Sciences, Lund University, Sweden \\ *Corresponding author. E-mail address: pernilla.ny@hs.mah.se (P. Ny).
} Lecturer) ${ }^{\mathrm{a}}$, Elisabeth Dejin-Karlsson, PhD, RN, RM (Senior Lecturer) ${ }^{\mathrm{a}}$, Anna-Karin Dykes, PhD, RN, RM

Received 28 October 2005; received in revised form 3 May 2006; accepted 9 May 2006

\begin{abstract}
Objective: To describe how men from the Middle East experience Swedish maternity and child health care. An integral part of the aim of this study has also been to describe the experiences of men from the Middle East when becoming and being a father in Sweden.

Design, setting and participants: an exploratory, qualitative study using focus-group discussions and individual interviews, with a semi-structured interview guide and content analysis. A total of 16 men participated. Ten Arabicspeaking men from the Middle East living in Sweden participated in three focus-group discussions. Six men from the Middle East living in Sweden, and speaking Swedish, participated in individual interviews.

Findings: three main categories were developed: meeting empathic professionals; finding new positions within the family; and experiencing social demands.

Key conclusions and implications for practice: seeing their partners being met individually and with empathy by midwives and child health-care nurses encouraged men to become involved in areas not previously open to them (i.e. pregnancy, childbirth and the care of babies and young children). As the women often lacked knowledge of Swedish, they depended on the help of their partners when meeting maternity and child health-care professionals. The men found the experience of living in an alien country difficult. They were often unemployed, felt they were a burden to their wives after emigrating to Sweden, and that they were no longer a suitable role model for their children.

(c) 2006 Elsevier Ltd. All rights reserved.
\end{abstract}

Keywords Fathers; Maternal health care; Emigration and immigration; Child health services

\section{Introduction}

Foreign-born men and women do not participate in the Swedish maternity and child health-care system to the same extent as Swedish-born men and women. The women come for their first visit later in pregnancy and do not participate in parental education to the same extent as Swedish parents (Plantin et al., 2003; Dejin-Karlsson and Östergren, 2004). Language is often perceived as being the main problem for the parents to be (Twinn, 1997; Darj and Lindmark, 2002). 
The importance of the provision of maternity care by a skilled practitioner is unquestionable for preventing maternal deaths. In Sweden during the 18 th century, a national policy favouring professional and free to all midwifery care reduced maternal mortality. By the 20th century, maternal mortality in Sweden was the lowest in Europe (World Health Organization, 1999), with a perinatal mortality rate of 5/1000 (The National Board of Health and Welfare, 2005). However, some women of foreign background have a higher risk of perinatal mortality when in Sweden than do Swedish-born women (Essén, 2000).

The husband's support and involvement is important for the transition to motherhood (Liamputtong and Naksook, 2003) and the experience of pregnancy (Kroelinger and Oths, 2000). If women are supported and encouraged by their partners in lifestyle changes, they are more likely to continue with actions beneficial for their health (SomersSmith, 1999; Ingram and Johanson, 2004). It is important for the father to be recognised and given the opportunity to communicate with the midwife in perinatal care. This applies to Swedish-born men living in Sweden (Persson and Dykes, 2002) and to men from different ethnic groups in the USA (Kroelinger and Oths, 2000). The importance of both parents taking equal responsibility for raising their children has long been addressed in Sweden, but some socio-economic conditions still affect the way men construct their fatherhood (Plantin, 2005). A father who is involved in the care of young children becomes a more engaged father (Chronholm, 2004); therefore, the fathers' perceptions of themselves as men and fathers can change (Plantin et al., 2003).

Research on men's parenting shows a diverse picture of their experiences and practices as fathers. Accordingly, fatherhood has come to be considered as socially constructed, shaped in the interplay between different relations and existing structures in the men's lives. This includes the relations within the family as well as societal expectations and conditions that surround the men and their parenthood. (Marsiglio, 1995; Brandth and Kvande, 1998; Plantin et al., 2003). However, 'cultural variations in the construction of fatherhood' (p.1257) is a largely neglected topic (Steinberg et al., 2000). Liamputtong and Naksook (2003) showed that the ethnic background of a woman's partner played a major role in his involvement and support in motherhood and mothering. It is important that we achieve a wider understanding of the social construction of fatherhood and the different opinions of fathers concerning participatation in maternity and child-health care. Men and women from the Middle East are one of the largest immigrant groups $(n=5590,2.1 \%)$ living in the Southern part of Sweden, (Malmö Stad, 2003). Men from the Middle East and their perception of health care for pregnant woman and young children in Sweden has not been previously described.

\section{Aim}

An integral part of the aim of this study has also been to describe the experiences of men from the Middle East when becoming and being a father in Sweden.

\section{Methods}

\section{Setting}

The study was conducted in two multi-ethnic cities in the South of Sweden. Focus groups and individual interviews were conducted. Focus group A was conducted at a university, group $B$ at a high school for foreigners and group $C$ at the Iraq Association. The first two individual interviews were conducted at a school for higher education, and the last four at an Arabic-Swedish association.

\section{Participants}

A total of 16 men were interviewed, and 25 were asked to participate in the study. Those not wanting to participate said they had other things to do or did not turn up for the interview. Ten men agreed to participate in three focus-group discussions in Arabic, and six other men accepted being individually interviewed in Swedish after being purposefully sampled by a member of the Arabic-speaking community. The inclusion criteria were men born in the Middle East who had become fathers while living in Sweden, and who were living in Sweden together with a partner of Middle-Eastern origin.

The first (A) and the last group (C) consisted of men who had lived in Sweden for more than 5 years, whereas the second group (B) had only lived in Sweden for 1-3 years. The participants in the individual interviews had been living in Sweden between 10 and 15 years. Their children's ages varied from 2-28 years in the individual interviews and from 3 weeks to 17 years in the focus groups. Participants with grown up children also had younger children living at home. Two of the wives were currently pregnant. Three men had a uni- 
versity degree and six of the men were employed. Two of the wives were working outside the home (interview B and 6).

\section{Data collection}

Focus-group discussion is a suitable method for exploratory research (Kitzinger, 1995; Twinn, 1997.) The goal is to discover new ideas and insights that can help people to explore and clarify their views (Morgan, 1998). The number of participants (three to four per group discussion) was suitable because of the need for a translator and cross-cultural research (Twinn, 1998). Following up the focus-group interviews with individual interviews allows deeper insight into certain aspects of the chosen topics (Krueger, 1998b; Strickland, 1999; Roer-Strier et al., 2005). The focus-group interviews were audiotaped and transcribed verbatim into English from Arabic by the translator. The individual interviews were audiotaped and transcribed verbatim into Swedish. The interview guide in the focus-group discussions focused on men's experience of maternity care for pregnant women and young children, their participation in the care, communication between midwife or nurse and the father to be about being a father in Sweden. In the individual interviews, the guide was extended to focus on advice given, the content of the advice and the involvement of the father in the care of small children (e.g. their use of parental leave). The interviewer asked a participant for his view about an earlier statement made by a previous participant. This made it possible for the participant to verify or decline his statement (the previous participants), with the purpose of validating the findings without seeking consensus (Burnard and Naiyapatana, 2004). All participants completed a preliminary questionnaire (patient data) before participating in the interviews, and gave their written consent to participate in the study. Before the interviews, all participants were informed about the purpose of the study and voluntary participation.

The questions were developed by the research team and the translator, who was born in Iraq and is a member of the Arab community; a health professional with a foreign-born background working in a multi-ethnic city district; and one of the researchers (PN) who earlier worked as a midwife in a multi-ethnic city district. The guide was tested (Krueger, 1998a; Small et al., 1999) by PN in two interviews with Swedish-speaking men from Iraq living in Sweden, and the topics were found to be culturally acceptable and relevant. Each topic was presented to the participants with a short introduction.

Each focus-group discussion took 2 hrs, and was conducted by the same moderator (PN) and translator. The individual interviews took between $45 \mathrm{mins}$ and $1 \mathrm{hr} 20 \mathrm{mins}$, and were conducted by $\mathrm{PN}$. The focus-group interviews were conducted during October to December, 2004, and the individual interviews during March and April, 2005.

Cross-cultural research that spans both cultural and language barriers needs special consideration. In this study, we maintained close contact with bilingual community workers and health-care staff from the Middle East in order to minimise linguistic and cultural misunderstandings. The inclusion of people who did not speak Swedish gave us a unique opportunity to participate in their experiences, which can differ from Swedish-speaking people because of their different background (Marshall and While, 1994). This study was concerned with immigrant men. Their reasons for emigrating are not investigated in this study.

The study was conducted according to the Swedish legislation of non-invasive studies and according to the Helsinki declaration of 1996 (Milton, 2002). Participants were fully entitled to withdraw their participation at any time.

\section{Data analysis}

Content analysis is a suitable method for crosslinguistic studies (Twinn, 1997). The text was analysed according to content analysis (Burnard, 1991), and divided into codes, subcategories and categories. Quotes reflecting the different subcategories are presented. First, the texts were read through several times individually by the authors (PN, LP, EDK, A-KD) to provide a sense of the whole. Thereafter, meaning units referring to the same content were divided into the same codes and, during the analysis, into sub-categories. Finally, the authors (PN, LP, A-KD), taking their pre-understanding (midwifery and sociology) and the study purpose into consideration, discussed the findings and agreed the three main categories of texts. The result of the content analysis was discussed with the translator, in order to exclude misinterpretations of the content resulting from the cross-cultural and cross-linguistic context (Graneheim and Lundman, 2004). Parts of the audiotape were translated from Arabic into English by an independent translator (Jones and Kay, 1992; Small et al., 1999) who was not involved in the study, in order to check for consistency in the translation. This resulted in no apparent differences in translation or content. 


\section{Findings}

Three main categories with their sub-categories were developed: (1) meeting empathic professionals, with sub-categories 'perception of information', 'a sense of security', and 'modifying advice'; (2) finding new positions within the family, with subcategories 'support during pregnancy and delivery' and 'being a father and a man'; and (3) experiencing social demands, with sub-categories 'to become integrated', 'to be a burden to your wife' and 'not being a suitable role model for your children'.

The findings are presented under three categories, each with its own sub-category (or categories), where $\mathrm{A}-\mathrm{C}$ represents the three different focus groups and 1-6 represents the six different individual interviews. Quotes have been used in reporting some of the findings for the purpose of clarifying the fathers' experiences. The Findings also include the fathers' experiences of being a father to older children, as some of the men had children of different ages.

\section{Meeting empathic professionals}

\section{Perception of information}

Health information from staff, and staff taking time to answer questions based on womens' individual needs, seemed to be important for the men. Several of the men stated that 'too much' information and information about risks could lead to anxiety. However, the practical and individually tailored advice from the midwife or child healthcare nurse was essential and aimed at the pregnant woman/mother:

She gets a lot of information, how it is with her and the baby and they also answer all her questions. There are so many things that worry her...... Yes they take care of the mother and child. (A)

Not all men had participated in the parental education offered to them, but all had opinions about it. Most liked receiving information in groups, although found some of the bad experiences dicussed by the other men frightening. Talking about risks threatened the desire for 'keeping it natural':

I don't encourage such meetings because the women begin to frighten each other, and the woman feels psychologically tired.... Even the man becomes afraid, just like the woman. Let's keep it natural. (C)
All the men stated that knowledge of Swedish is important when taking part in group education, as this is mostly offered in Swedish. The men suggested that this could be solved by having different groups in different languages or to use a translator. This would make it possible for the participants to understand and actively participate in discussions.

\section{A sense of security}

The fathers felt secure if staff were knowledgeable and well-informed about the health of the woman and her baby during pregnancy and childbirth:

I think they give the instructions and information and one feels that there is control over the baby; not only the baby but the mother also. (C)

The men compared their experiences of pregnancy and childbirth in Sweden with their experiences back home. They discussed the lack of control often found in health-care services in their country:

Compared to Iraq, (where) there is no such control and we are proud to have such services here. We tell the family back home about this. (C)

As a result of increased participation, the men felt respect for the women during childbirth. They could see that the women and their babies were treated kindly and were offered medical resources. Such recourses as empathy and medical technology were considered to be important to the fathers:

The health care in Sweden is unique and it is accepted by everyone. (6)

\section{Modifying advice}

Advice given by the maternity and child-health care services in Sweden was compared with the experiences and advice given back home. This was usually given by relatives, often the man's mother or sisters. If better advice was offered in Sweden, a compromise was often made. The men stated that old and new advice were often used in conjuction with older traditions. Some advice was considered strange, but, after talking to the midwife or child health-care nurse, the advice was often accepted.

To be honest, something was strange, but that doesn't mean that we didn't do it, on the contrary. The thing that was strange for us is that the child should take AD-drops for about 6 years!! We went back and asked her, do you really mean 6 years? And she said yes, 6 years. (A) 


\section{Finding new positions within the family}

\section{Support during pregnancy and delivery}

Several men mentioned that participating in pregnancy and birth opened up a new world for them. They attended midwife and child health-care nurse appointments with their wives, and often acted as interpreter. In a way, this inhibited the women, as their dependence on their husbands was greater than in their native countries:

A woman cannot manage herself due to lack of knowledge in Swedish. She gets very dependent on her husband.

In their native countries, it was the female network, with the mother-in- law in charge, that helped and took care of women during pregnancy and childbirth:

In Sweden the man has taken her place. (1)

But not all men attended midwife and child health-care appointments with their wives and babies. The reasons for not doing so could be that the woman preferred a female friend (3). One man in group (B) did not want to join his wife during the birth because 'it was not a place for men'. His wife was to be accompanied by a female relative or friend and, according to the man, this was something that they had agreed upon.

To have the opportunity to participate in your own child's birth was a strong experience according to the men. By accompanying their wives, they could also help during the birth. Men in two of the groups $(B, C)$ emphasised the importance of taking part in the birth. They acknowledged that childbirth was a tough situation, and seeing their wives in this situation would help them gain a deeper understanding of their experience:

You see your baby come out a centimetre after the other, and you become very happy. (C)

\section{Being a father and a man}

As stated earlier, the men described their experiences of being a father to children of different ages. The men found it difficult bringing up children in a society other than their own. The children are involved in a totally different way in the Swedish society, at school and with friends other than grown-ups. It is important as a parent to be able to handle these new ways in order to take a stand for which roles and customs are to be used within the family. A good father keeps a good relationship with his children where they respect each other. One man said:

I see in this society that I have to go with my daughter son or wife, side by side, I must know that there are laws. I have to keep a good relation and confess that it's I who is coming to this society. (C)

Several men stated that a good father is a person who can combine the two worlds, bringing up the children as tradition calls for but in a new country. Two fathers stated that it was difficult to find the role as a father in Sweden and that one doesn't feel the responsibility for being a father here, but it is important that you take that responsibility:

If you care for your children you have to start early and show them how to behave. (5)

A father in Sweden is merely a father. (B).... he has no role. Here it is the country's child I mean. You don't feel that you are responsible as a father here. (B)

Becoming a father was life-changing, and brought with it big responsibilities for the care and upbringing of the children. To spend time with your children, being honest and having a job were important aspects of the father's role. The father's personality, and society's perception of the role of the man, affects how a person acts as a father, both in their native country and also in Sweden:

I believe that there is a huge difference, from which country you come from, to which culture you belong to, and also it differs within the same country and the different classes in the community, coming from the countryside or the city. Are you open minded or stuck to the old thoughts and beliefs, educated or not, so it depends on so many things. (B)

Only one man (6) discussed the importance of using parental leave in Sweden, as it can positively influence the relationship between the father and child.

In Sweden, both parents may make use of parental leave, which is of a total of 480 days, of which 2 months is exclusively for one parent (RFV, 2002).

It would be perfect to stay six months with your child, but can you handle it and accept it as a father? (6)

All the men left the parental leave to their wives, but they knew that a certain number of days were reserved for them as fathers and could not be used by their partners:

I left this time to my wife, and after work I go and stay with them. (A) 


\section{Experiencing social demands}

\section{To become integrated}

Several of the men stated that being employed made it possible to take part in society. As a foreigner, you have to learn the laws and language of the host country. However, many of the men said that neither of these were possible without a job. Being unemployed created feelings of isolation and lack of productivity.

I have been working for five years now. My psychological and physical condition is much better than when I was without a job and I feel as a positive person in the society. Nobody says to me that I don't pay the taxes anymore. You get to mix with the Swedish society. Those who work, have more respect and recognition in the community. (C)

Some men stated that, in Sweden, men had fewer legal rights than women, and that woman could even get men imprisoned if they wanted to. When a man is unemployed, the social situation changes, as the man loses his status and the woman is better off without him. Having a husband with no job might give the woman less freedom than in Iraq because the man would spend all his time with the family:

The father is without a job and lives on social welfare. The man feels that he is weak and the wife says that you don't do anything for me. (C)

In this study, the men were asked if the length of their stay in a country would affect their ability to integrate? However, the men stated that it was rather the conditions (i.e. status of the area you live in, the school you go to and your own ambitions) that determined this. Becoming integrated can be difficult because of structural social problems, such as isolation within segregated areas, crowded housing and no opportunites for employment. This is what many immigrants suffer from according to the men:

The ambition makes you want to learn as fast as possible, plus the environment one is living in. The environment and the ambition are the factors that help create a man that reacts with the society. (C)

To be a burden to your wife and not being $a$ suitable role model for your children

The men stated that, in Sweden, the economic situation was more difficult than in Iraq. Their children missed many things. Not being the sole provider for the family was also hard for the men in their relationships with their wives and children, because it was difficult to be a good role model if you were unable to show your children that you could take care of them financially. A better economic situation made it possible to save money, buy things, go on vacation and have better living conditions:

Especially if one is used to pay for everything in the homeland. Just like me, I was married in my homeland and I paid for everything. And now it's different. Here you are an extra weight to your wife. If you have money and work, you are going to teach your son to work also. You become a role model to your son. (B)

\section{Discussion}

Trustworthiness is important for qualitative research, and includes concepts such as stability and credibility. The authors (PN, LP and A-KD) analysed the data separately in order to ensure that the descriptive categories are in accordance with the interview material. The text was read multiple times to achieve stability (Weber, 1990; Krippendorff, 2004) and discussed by the three researchers to strengthen its credibility (Krueger, 1998b; Weber, 1990; Graneheim and Lundman, 2004). To maximise the quality of the data, it is important to interview participants in their first language (Twinn, 1998) and use the same translator in all the interviews (Twinn, 1997) as was done in the three focus groups.

The number of participants per group (three to four) was found suitable depending on the explorative and cross-cultural nature of the study and the use of translator. Twinn (1998) also conducted a content analysis of transcripts in English translated from Chinese. By having small groups, we eliminated the risk of frustration resulting from participants not having enough time or opportunity to express themselves in larger groups. We followed the concept of 'higher involvement' where the participants were seen as the experts (Morgan, 1998).

Several focus-group discussions were conducted, which increased the credibility of the research (Sim, 1998). This was combined with six individual interviews. The reason for not using the same participants in both the focus groups and individual interviews was the desire for variety as proposed by Twinn (1997). During the second focus-group discussion and individual interview, similarities in the discussion were identified, especially while discussing preventive health care for pregnant women and young children. 
In qualitative studies, it is not possible to make generalisations, but the findings might be transferable if a 'snapshot' is offered of a particular context of a particular time (Burnard and Naiyapatana, 2004). It would perhaps be unrealistic not to think that members of the same group might have something in common as stated by Sim (1998) and Burnard and Naiyapatana (2004). This can be strengthened by diverse sampling. The men in this study were geographically and socially separate; however, they had a shared view of the field of interest.

One disadvantage of focus-groups interviews could be that one individual may dominate the group (Morgan, 1998). This was the case in focus group A, but as the moderator was knowledgable about the interview technique, the other members soon got involved. Another disadvantage is that the moderator might find it difficult to keep the group focused (Twinn, 1998) without losing the inductive nature of the study. This was the case in groups $A$ and $\mathrm{C}$ at some point; however, after explaining the aim of the focus group, the participants were able to become refocus. After a while, participants reminded each other to keep the aim of the focus group in mind, and to allow others to participate in the discussion.

Conducting interviews in the participants' native language seems to be important. Even though the participants in the individual interviews had lived in Sweden for several years, they were limited in their ability to talk about private matters in Swedish. Difficulty in expressing their true meaning may have affected the outcome of these interviews. This was taken in to consideration in interpreting the results (Small et al., 1999). This was also seen in Hjern et al. (2001).

Conducting the analysis from the Arabic transcripts may have increased the trustworthiness of the study (Burnard and Naiyopatana 2004). However, at the time of the study, no bilingual Arabic and Swedish speakers who were familiar with the content analysis method were available. It is also important for the researcher to be aware of their own racial identities and cultures when interpreting data (Barbour and Kitzinger, 2001).

The men's perception of the recruiter plays a significant role (Twinn, 1998). The recruiter, who was known within the community, probably played a major role in reaching a wider number of men. The recuiter takes on a special 'bridging' role, as they need a good understanding of different languages and cultures, and then need to be able to connect the two (Small et al., 1999). After the interviews, all the men seemed open to discussing the subject of this study, as shown in similar studies
(Twinn, 1998). One man said 'this is something that all men should do' (B); another stated that 'the questions were very clear and important' (A); and, in focus group $C$, men said 'if you live in this country these are things you need to know'.

The dialogue differed between the groups, but the most obvious difference was between groups $B$ and $C$. Participants in group $B$ were still in the first phase of immigration and trying to understand their new country (Smith and Shaw, 2004), the way of living, and the Swedish maternity and child healthcare system. In this group, the children were young, their wives pregnant, or both. The reality was different in many ways. For Group C, it was being able to take part in the woman's world. Because they had been in Sweden for a longer time than group $B$, it was possible to reflect on their overall situation in Sweden and how it had turned out. Samarasinghe and Arvidsson (2002) also saw differences in the status of the immigrant families on the basis of their length of stay in the host country. Because of their older children, they were more keen to discuss matters regarding the upbringing of children in a different country and how their socioeconomic situation affected them as fathers. The participants in the individual interviews had been in Sweden longer and had reflected on how it had all turned out, but had different experiences of Swedish maternity and child health care and fatherhood because of the different ages of their children. However, they all shared the common experience of being an immigrant man in Sweden who had been given the opportunity of participating in a new field, that of maternity and child health care, an area usually the reserve of women.

\section{The professional individualised care}

The men participated in preventive health care to support their wives and children. This is also seen in previous research by Olsson and Janson (2001). However, they were not actively involved in the communication between the midwife and the woman in prenatal care; only by being present could they support the woman. If the woman did not speak Swedish, the men often acted as interpreter. The empowering behaviour of the midwives and child health-care nurse's created a sense of security and feeling that the midwife and nurse were knowledgeable and could be trusted. Hjern et al., (2001) found that $57 \%$ of the participant immigrant groups expressed a high level of confidence in the Swedish health services. The positive relationship between the caregiver and the woman gave the men a better chance to be 
more involved and, by doing so, the communication between the parents and staff could improve (Jansson et al., 2001; Fredriksson et al., 2003). Good care seems to be dependent on communication, preferably by a known health worker in a familiar setting (Ny et al., 2006), the ability to meet the individual just as they are, and taking time to answer questions based on the individual woman (Persson and Dykes, 2002).

The experiences of being part of the birth, seeing the woman giving birth and being able to be there for her was mentioned as a strong experience. This was also seen in Somali men living in Sweden (Wiklund et al., 2000). This experience increased their respect for the woman. The midwife at the delivery unit also seemed open to the involvement of the partner, according to the men. Olsson and Jansson (2001) noticed in their study that the involvement of the partner differed because of the attitude of the midwife.

Some of the men were not keen on the idea of parental groups for fathers, mostly because of language difficulties. This is also seen in the study of Somali men living in Sweden by Wiklund et al. (2000). As some of the men discussed, Arab men do not gather in groups to discuss pregnancy and birth. But they all shared the common experience of being an immigrant man in Sweden who had been given the opportunity to take part in a new field, that of maternity and child health care. An area that was up to now the reserve of women. In Sweden, the couple had only each other and needed to help one another; therefore, the relationship between the parents seems to be important for the involvement of the father in the care of young children, as seen in Sarkadi et al. (2004).

\section{Living in an alien country}

The findings of this study showed how social factors, such as being unemployed and being between different cultures, affected the social construction of fatherhood (Marsiglio, 1995; Brandth and Kvande, 1998; Plantin et al., 2003). The identities of being a father, partner and man seem to be closely connected, and we have chosen not to separate them. The relationship between fatherhood and masculinity is a neglected area, which is surprising as the two areas seem to be linked. A man's view of himself as a man will affect his role as a father and therefore his fathering actions. (Plantin et al., 2003; Roer-Strier et al., 2005).

The interviews were complex, as the men were conservative in their views: 'we Arab people do this'; 'it is natural for women to take care of the children'; 'men do not know how to do such things', but they were also open to new approaches: 'it is up to the individual to decide'. These three quotes were made in group B whose participants had lived in Sweden for a shorter period of time. The men saw themselves as the breadwinners, as having responsibility for their families, which is also found in Plantin et al. (2003) when interviewing Swedish-born men. The men also discussed how difficult it was to be a role model for your children when you had no job and no status; the similar result was shown among immigrant men in Canada and Israel (Roer-Stirer et al., 2005). Being supported by Social Welfare, being unemployed and having a sense of not being needed, either by families or society, made it difficult for the men to live up to their perception of themselves as the head of the family, what can be expressed as 'traditionally defined masculinity' (White, 1994, p.119).

The different position offered to immigrant women by Swedish society affected the men's opinion about their wives and their place in society. The wife could in some cases be perceived as a threat to the family structure and to them as men. This was because men's perception of themselves as the responsible head of their families, with the status and power this entailed for them (White, 1994) was questioned, and the family structure was threatened. Their traditional attitudes towards women were no longer valid, as they differed significantly from the attitudes dominant in Swedish society. When individuals migrate, an individual's cultural identity will change at different levels, such as individual, kinship and social levels. This can lead to conflict within the family as a result of altered positions of the mother and father (Smith and Shaw, 2004). This situation can challenge the traditional view of fatherhood but also coerce men to adapt to new ways in their relationship towards their children and partner.

The men spoke positively about taking part in the female world (e.g. pregnancy, childbirth, more involvement in the children). They did not mention this as something they gained (Wiklund et al., 2000), only that they lost parts of their male world (e.g. not being the bread winner, being unemployed). The former was not considered as a conflict, but it can become a conflict when the woman challenged the male world. This occurs in Sweden because of the different legal rights women have here (e.g. the right to divorce and the right to abortion). 


\section{Conclusions}

The men were very positive at being invited to participate in information gathering about pregnant woman, and learning how to better improve the woman's situation during pregnancy, how to care for babies and young chidren, and to be able to take part in the birth. This was considered an important event in their lives. According to the men, language was a main barrier for not participating in parental education. From the men's perspective, it has also given them knowledge about immigrants' views of fatherhood in Sweden and how different social structural problems, such as unemployment, poor economy, the inability to speak Swedish and the upbringing of children who are between two different cultures, affect them. The men emphasised factors affecting them in their ability to handle their view of themselves as men, which in turn affects how they behave as fathers and partners.

\section{Implications for practice and further research}

The findings can lead to an improved way of working in maternity health-care, by involving the men at an early stage of pregnancy and by making it easier for them to continue with their involvement at the child health care centres and the care of their babies and young children. The importance of involving men early in the care of their children is important for the improved health of their partners and their young children, and also for the long-term effect on the relationship within the family and the growing children (Bronte-Tinkew et al., 2006).

Further research is needed to understand the effect of migration on health, health-seeking behaviour, parenthood and gender by investigating more thoroughly how socio-economic factors, such as housing, unemployment and status, affects immigrant men in Sweden. It is also of future interest to learn how immigrant mothers from the Middle East experience the preventive health-care for pregnant woman and babies and young children, the involvement of men in pregnancy and childbirth, and being a mother in Sweden.

\section{Acknowledgements}

To all the men of the Arabic-speeking community in the Southern part of Sweden for their participation in the study, and their valuable opinions about this important subject. Thanks also to Nabil Rauf AlDujaili, Chairman at the Iraq association and at the
Arabic and Swedish association in the southern parts of Sweden, and to Ingela Olson. The study was funded by the Department of Social Work and Department of Caring at Health and Society, Malmo University, Sweden and the Swedish Society of Nurses.

\section{References}

Barbour, R.S., Kitzinger, J., (Ed.), 2001. Developing Focus Group Research: Politics, Theory and Practice, 2001, Sage Publications Ltd, London

Brandth, B., Kvande, E., 1998. Masculinity and childcare: the reconstruction of fathering. The Sociological Review 46, 293-314.

Bronet-Tinkew, J., Moore, K.A., Capps, R.C., Zaff, J., 2006. The influence of father involvement on youth risk behaviors among adolescents: a comparison of native-born and immigrant families. Social Science Research 35, 181-209.

Burnard, P., 1991. A method of analyzing interview transcripts in qualitative research. Nurse Education Today 11, 461-466.

Burnard, P., Naiyapatana, W., 2004. Culture and communication in Thai nursing: a report of an ethnographic study. International Journal of Nursing Studies 41, 755-765.

Chronholm, A., 2004. Dad on Parental Leave: Men's Experiences of Shared Parental Leave (doctoral thesis) (in Swedish). University of Gothenburg, Sweden.

Dejin-Karlsson, E., Östergren, P-O., 2004. Country of origin, social support and the risk of small for gestational age birth. Scandinavian Journal of Public Health 32, 442-449.

Darj, E., Lindmark, G., 2002. Not all women use maternal health services. Language barriers and fear of the examination are common. Läkartidningen 99, 41-44.

Essén, B., 2000. Increased perinatal mortality among subSaharan immigrants in a city-population in Sweden. Acta Obstetrica Gynecologica Scandinavia 79, 737-743.

Fredriksson, G.E.M., Högberg, U., Lundman, B.M., 2003. Postpartum care should provide alternatives to meet parents' need for safety, active participation, and 'bonding'. Midwifery 19, 267-276.

Graneheim, U.H., Lundman, B., 2004. Qualitative content analysis in nursing research: concepts, procedures and measures to achieve trustworthiness. Nurse Education Today 24, 105-112.

Hjern, A., Haglund, B., Persson, G., et al., 2001. Is there equity in access to health services for ethnic minorities in Sweden? European Journal of Public Health 11, 147-152.

Ingram, J., Johanson, D., 2004. A feasibility study of an intervention to enhance family support for breast feeding in a deprived area in Bristol, UK. Midwifery 20, 367-379.

Jansson, A-K., Peterson, K., Udén, G., 2001. Nurses first encounter with parents of new-born children- public health nurses views of a good meeting. Journal of Clinical Nursing 10, 140-151.

Jones, E.G., Kay, M., 1992. Instrumentation in cross-cultural research. Nursing Research 40, 186-188.

Kitzinger, J., 1995. Introducing focus groups. British Medical Journal 311, 299-302.

Krippendorff, K., 2004. Content analysis. An Introduction to its Methodology, 2nd edn. Sage Publications Ltd., California.

Krueger, R.A., 1998a. Developing questions for focus groups. The focus group kit3. Sage Publications Ltd., Thousand Oakes, California. 
Kreuger, R.A., 1998b. Analysing and reporting focus group results. The focus group kit6. Sage Publications Ltd., Thousand Oakes, California.

Kroelinger, C.D., Oths, K.S., 2000. Partner support and pregnancy wantedness. Birth 27, 112-118.

Liamputtong, P., Naksook, C., 2003. Perceptions and experiences of motherhood, health and the husband's role among Thai women in Australia. Midwifery 19, 27-36.

Malmö stad, 2003. Statistics for Malmo citydistricts 2003, Malmö stad 2003.

Marshall, S.L., While, A.E., 1994. Interviewing respondents who have English as a second language: challenges encountered and suggestions for other researchers. Journal of Advanced Nursing 19, 566-571.

Marsiglio, W. (Ed.), 1995. Fatherhood: Contemporary Theory, Research and Social Policy. Sage Publications Ltd., Thousand Oaks, Califonia.

Milton, A., 2002. Världsläkarförbundets Helsingforsdeklaration (World Medical Association and the Helsinki declaration). Läkartidningen 99, 1214-1216, 2002 (In Swedish).

Morgan, D.L., 1998. Planning focus groups. The focus group kit2. Sage Publications Ltd., Thousand Oakes, California.

Ny, P., Dejin-Karlsson, E., Udén, G., Greiner, T., 2006. Health education to prevent anemia among women of reproductive age in southern India. Journal of Health Care For Women International 27, 131-144.

Olsson, P., Janson, L., 2001. Patterns in midwives' and expectant new parents 'ways of relating to each other in ante- and postnatal consultations. Scandinavian Journal of Caring Science 15, 113-122.

Persson, E.K., Dykes, A-K., 2002. Parents experience of early discharge from hospital after birth in Sweden. Midwifery 18, 53-60.

Plantin, L., Månsson, S-A., Kearney, J., 2003. Talking and doing fatherhood: on fatherhood and masculinity in Sweden and Britain. Fathering 1, 3-26.

Plantin, L., 2005. Different classes, different fathers? On fatherhood, economic conditions and class in Sweden (in press).

RFV, 2002. The National Social Insurance Board.

Roer-Strier, D., Strier, R., Este, D., Shimonis, R., Carke, D., 2005. Fatherhood and immigration: challenging the deficit theory. Child and Family Social Work 10, 315-329.

Sarkadi, A., Kristansson, R., Bremberg, S., 2004. The importance of fathers for the health of children and teenagers: a systematic review of longitudinal studies (in Swedish). Statens folkhälsoinstitut, Sandviken, 2004, 17.
Samarasinghe, K., Arvidsson, B., 2002. It is a different war to fight here in Sweden: the impact of involuntary migration on the health of refugee families in transition (in Swedish). Scandinavian Journal of Caring Science 16, 292-301.

Sim, J., 1998. Collecting and analyzing qualitative data: issues raised by the focus group. Journal of Advanced Nursing 28, 345-352.

Small, R., Yelland, J., Lumley, J., Liamputton Rice, P., Cotronei, V., Warren, R., 1999. Cross-cultural research: trying to do it better 2. Enchancing data quality. Australian and New Zealand Journal of Public Health 23, 390-395.

Smith, G.D., Shaw, M., 2004. Cultures of health, cultures of illness. British Medical Bulletin 69, 129-141.

Somers-Smith, M.J., 1999. A place for the partner? Midwifery 15, 101-108.

Steinberg, S.U., Kruckman, L., Steinberg, S.T., 2000. Reinventing fatherhood in Japan and Canada, Social Science and Medicine 50, 1257-1272.

Strickland, C.J., 1999. Conducting focus groups cross-culturally: experiences with Pacific Northwest Indian people. Public Health Nursing 16, 190-197.

The National Board of Health and Welfare, 2005. Medical birth registration 2003 (2005:4), Socialstyrelsen, Stockholm; http: / /www.sos.se (last accessed 1 June 2006).

Twinn, S., 1997. An exploratory study examining the influence of translation on the validity and reliability of qualitative data in nursing research. Journal of Advanced Nursing 26, 418-423.

Twinn, S., 1998. An analysis of the effectiveness of focus groups as a method of qualitative data collection with Chinese populations in nursing research. Journal of Advanced Nursing 28, 654-661.

Weber, R.P., 1990. Basic Content Analysis, 2nd edn. Sage Publications Ltd., Thousand Oakes, California.

World Health Organization, 1999. Reduction of maternal mortality: a joint WHO/UNFPA/UNICEF/WORLD BANK Statement. WHO, Geneva.

White, N.R., 1994. About fathers: masculinity and the social construction of fatherhood. Australian and New Zealand Journal of Sociology 30, 119-131.

Wiklund, H., Aden, A.S., Högberg, U., et al., 2000. Somalis giving birth in Sweden: a challenge to culture and gender specific values and behaviours. Midwifery 16, 105-115 www.odontologi.gu.se/etik/helsingfors/htlm.

Available online at www.sciencedirect.com 